\title{
GOVERNANÇA CORPORATIVA E VALOR DA FIRMA: \\ um estudo de empresas brasileiras do setor elétrico
}

\section{1-Flávia Ferreira Marques Bernardino}

Mestre em Administração pela Universidade Federal de Uberlândia (FAGEN/UFU), Brasil.

Professora do Instituto Federal do Triangulo Mineiro (IFTM), Brasil.

flaviafmarks@hotmail.com

\section{2-Fernanda Maciel Peixoto}

Doutora em Administração pela Universidade Federal de Minas Gerais (CEPEAD/UFMG), Brasil.

Professora Adjunta da Faculdade de Gestão e Negócios da Universidade Federal de Uberlândia (PPGA/FAGEN/UFU), Brasil.

fmacielpeixoto@gmail.com

\section{3-Roberto do Nascimento Ferreira}

Doutor em Administração pela Universidade Federal de Lavras (UFLA), Brasil. Professor Adjunto da Universidade Federal de São João Del-Rei (UFSJ), Brasil. roberto@ufsj.edu.br

\author{
Diego Maganhotto Coraiola - Editor Geral \\ Editor responsável pela submissão: \\ Carlos Patricio Samanez. \\ Artigo analisado via processo de revisão duplo cego (Double-blind). \\ Recebido em: 04/02/2014 \\ Aprovado em: 06/05/2014 \\ Última Alteração: 30/04/2014
}

* Contato Principal: Rua João Carlos da Silva, 527, Apto 201. Constantino, Patrocínio - MG, Brasil. CEP: 38740-000. 


\title{
GOVERNANÇA CORPORATIVA E VALOR DA FIRMA: UM ESTUDO DE EMPRESAS BRASILEIRAS DO SETOR ELÉTRICO
}

\section{RESUMO}

Esta pesquisa pretendeu analisar os efeitos da adoção de mecanismos de governança corporativa pelas empresas de capital aberto do setor elétrico brasileiro sobre seu valor de mercado, no período de 2008 a 2012. Para tanto, construiu-se um índice de qualidade da governança, pelo método Análise de Componentes Principais, envolvendo 12 variáveis representativas dos mecanismos de governança reconhecidos pela Teoria de Agência, baseado nos trabalhos de Correia (2008) e Peixoto (2012). Tal índice foi utilizado nas regressões com dados em painéis, em associações com Q de Tobin e MBA (market-to-book sobre o ativo). Os resultados revelaram uma relação negativa e significativa, que pode estar associada às particularidades do setor elétrico, ao fato de o mercado de capitais brasileiro ser pouco desenvolvido, ou mesmo ao reduzido nível de liquidez das empresas.

\author{
Palavras-chave \\ Governança Corporativa. Valor de Mercado. Análise dos Componentes Principais.
}

\section{CORPORATE GOVERNANCE AND FIRM VALUE: A STUDY OF BRAZILIAN COMPANIES IN THE ELECTRIC SECTOR}

\section{ABSTRACT}

This research aimed to examine the effects of adopting corporate governance mechanisms on the market value of publicly traded companies of the Brazilian electric sector in the period 2008-2012. To that end, a governance quality index was constructed, using the Principal Component Analysis method, involving 12 variables representing the governance mechanisms recognized by the agency theory, based on works by Correia (2008) and Peixoto (2012). This index was used in the regressions with panel data, in association with Tobin's Q and MBA (market-to-book on assets). The results revealed a negative and significant relationship, which may be linked to the particularities of the electricity sector, or to the fact that the Brazilian capital market is underdeveloped, or even to the low level of liquidity of companies.

\section{Keywords}

Corporate Governance. Market value, Principal Components Analysis. 


\section{Introdução ${ }^{1}$}

A qualidade da governança corporativa influencia no valor da firma? Definitivamente, as respostas para este questionamento não são conclusivas, o que pode ser comprovado pela vastidão de estudos que relacionam uma melhoria da performance operacional, financeira e consequente reconhecimento pelo mercado de capitais com a qualidade das práticas de governança nas empresas (Almeida, Klotzle \& Pinto, 2013; Carvalhal-da-Silva \& Leal, 2005; Correia, 2008; Cremers \& Ferrell, 2010; Demsetz \& Villalonga, 2001; Ehikioya, 2009; Gompers, Ishii \& Metrick, 2003; Gotardelo, 2006; Klapper \& Love, 2004; Lameira, Ness \& Soares, 2005; Silveira, Barros \& Famá, 2005; Velasquez, 2008).

De acordo com o Instituto Brasileiro de Governança Corporativa (IBGC, 2009), as boas práticas de governança têm como objetivo aumentar o valor da sociedade, facilitar seu acesso ao mercado de capitais e contribuir para a continuidade das empresas. Silveira (2002) acredita que as boas práticas de governança corporativa afetam o desempenho e valor das organizações, as quais apresentam melhor resultado e, por isso, são melhor avaliadas pelo mercado, se comparadas a empresas negligentes com os mecanismos de governança.

A maior parte da literatura nacional e internacional, sobre a relação entre o valor da firma e a governança corporativa, documenta que melhores práticas de governança corporativa estão associadas a uma maior valorização da firma (Correia, 2008; Gompers et. al., 2003; Jensen \& Meckling, 1976; Klapper \& Love, 2004; Lameira, 2007; Lameira et. al., 2005; La Porta, Lopez-de-Silanes, Shleifer \& Vishny, 2002; Lima, 2009; Macedo \& Corrar, 2009; Silveira et al. 2005; Yermack, 1996).

Não obstante, não é unânime que a adoção de boas práticas de governança implique, efetivamente, em maior valor para as empresas, bem como não é claro se a relação custo $x$ benefício associada com a implementação dos mecanismos de uma boa governança seja positiva (Bruno \& Claessens, 2010; Chhaochharia \& Grinstein, 2007; Gillan, Hartzell \& Starks, 2003; Peixoto, Amaral, Correia \& Neves, 2013).

Diversos autores se valeram da construção de índices para medir a qualidade das práticas de governança nas empresas (Almeida, Santos, Ferreira, \& Torres, 2010; Bebchuk, Cohen \& Ferrell, 2009; Black, Carvalho \& Gorga, 2012; Braga-Alves \& Shastri, 2011; Carvalhal-da-Silva \& Leal, 2005; Correia, Amaral \& Louvet, 2011; Durnev \& Kim, 2005; Gompers et. al., 2003; Klapper \& Love, 2002; Lopes \& Walker, 2008; Mello, 2007; Silveira, 2004; Vieira, 2010).

No entanto, várias críticas têm sido feitas com relação ao uso e elaboração dos índices de governança. Mello (2007), por exemplo, questiona o uso de índices baseados em perguntas sobre a adoção de determinadas práticas de governança corporativa, cada uma retornando uma resposta objetiva e binária (sim ou não), coletada por meio de dados secundários.

Martynova e Renneboog (2010) apontam algumas limitações ao índice criado por La Porta, Lopez-deSilanes, Shleifer e Vishny (1998), tais como: o sistema legal tomado como referência é o americano, ignorando os princípios regulamentares que prevalecem em outros países; além disso, seus índices são estáticos, se reportando a um período que não reflete as verdadeiras diferenças entre os sistemas jurídicos nacionais atuais. Para os referidos autores não existem ainda índices que capturem adequadamente práticas relevantes de governança corporativa.

Para Peixoto et al. (2013), a governança corporativa pode assumir diferentes papéis, considerando o contexto econômico de cada país. Ou seja, a GC pode assumir funções distintas em momentos de crise ou estabilidade econômica. Durnev e Kim (2005), Francis, Khurana \& Pereira, (2005), Klapper e Love (2004), La Porta et al. (2002) e Ammann et al. (2011) são alguns dos trabalhos que trataram da relação entre governança e valor no contexto internacional, levando em consideração as especificidades de seus países de origem.

Ammann, Oesch e Schmid (2011) investigaram a relação entre a governança corporativa e o valor da empresa, com base em um conjunto de dados disponibilizado pelo Governance Metrics International (GMI), envolvendo 6.663 observações empresa-ano, de 22 países desenvolvidos, no período de 2003 a $2007.0 s$ autores encontraram que, independentemente de os atributos serem considerados individualmente ou agregados em índices, eles apresentam um efeito positivo e significativo sobre o valor da empresa, medido pelo Q de Tobin.

Por sua vez, Bebchuk et al. (2009), questionam os índices que algumas empresas utilizam para mensurar a qualidade da governança, como o disponibilizado pelo Institutional Shareholder Services (ISS), uma das mais influentes empresas de consultoria, cuja métrica baseia-se em 61 elementos de governança. Para os citados autores, em um conjunto com elevado número de atributos de governança poucos deles possuem significado real. Além disso, corre-se risco de atribuir pesos àqueles que não tenham tanta importância e subavaliar os atributos que realmente importam, proporcionando assim uma medida não muito precisa da qualidade da governança.

A presente pesquisa adotou a concepção de governança corporativa proposta pela Teoria da Agência $^{2}$ e se propôs a verificar como a qualidade da governança afeta o valor de mercado das organizações, respondendo a seguinte questão: Qual o efeito da governança corporativa sobre o valor das firmas do setor elétrico brasileiro no período de 2008 a 2012 ? 


\section{Flávia Ferreira Marques Bernardino, Fernanda Maciel Peixoto, Roberto do Nascimento Ferreira}

O arcabouço que fundamenta a teoria da agência aponta como alvo da governança corporativa seus mecanismos, que visam alinhar os interesses dos agentes envolvidos e reduzir os conflitos entre eles. Para tanto, as companhias valem-se de um ou mais atributos de governança, que não possuem, necessariamente, a mesma importância em todos os países. Isto é, uma dimensão de governança que é muito importante para o contexto de certo país pode não ser para outro (Correia, 2008).

Alguns estudos demonstraram que, em contextos como o brasileiro, os conflitos de agência se dão, principalmente, entre acionistas controladores e minoritários. Assim, os impactos dos mecanismos de governança podem assumir diferentes proporções, diante de algumas peculiaridades do Brasil, como: a forte concentração da propriedade e controle (Valadares \& Leal, 2000; Leal, Carvalhal-da-Silva \& Valadares, 2002); conselhos de administração com papéis restritos e representativos dos acionistas majoritários (Valadares \& Leal, 2000) e baixo nível de proteção aos direitos dos acionistas minoritários (Carvalhal-da-Silva \& Leal, 2005).

Dessa forma, o objetivo principal deste estudo é analisar os efeitos da adoção de mecanismos de governança corporativa pelas empresas de capital aberto do setor elétrico brasileiro sobre seu valor de mercado, no período de 2008 a 2012, considerando os problemas de agência específicos do nosso país.

A escolha do setor elétrico foi motivada pela sua expressividade na economia do país, considerado um setor de importância estratégica, com crescimentos superiores ao PIB (Produto Interno Bruto) brasileiro. Enquanto o PIB no Brasil cresceu apenas 0,9\% de 2011 a 2012, o consumo de energia elétrica teve uma expansão de 3,8\% e a oferta interna de energia elétrica em 2012 apresentou crescimento de 4,4\% em relação a 2011 (EPE, 2012). Aliado a esse fato, o crescente movimento de adesão aos NDGC (Níveis Diferenciados de Governança Corporativa) da BM\&FBovespa pelas empresas do setor indica que elas estão buscando alinhar-se às melhores práticas de governança corporativa (Mello, 2007).

Ademais, o setor elétrico apresenta algumas singularidades, tais como a impossibilidade de estocar seu principal produto (Losekann, 2003). Este setor é fortemente regulado e dependente de políticas públicas, com relação a preço, investimentos, margens e retornos. O investimento de capital é intensivo e isso revela a importância do acesso ao mercado de capitais e ao financeiro e da constante investigação por parte dos stakeholders. (Bernini, 2010).

Para Beys (2009), o marco regulatório de 2004 modificou a configuração da matriz elétrica brasileira, alterando os padrões operacionais nos segmentos de geração, comercialização, transmissão e distribuição, reduzindo as margens das empresas do setor e, consequentemente, o retorno dos acionistas.

Após o marco regulatório de 2004, o setor elétrico passou a apresentar um novo arranjo institucional, onde os principais agentes são: Conselho Nacional de Política Energética (CNPE), Ministério de Minas e Energia (MME), Empresa de Pesquisa Energética (EPE), Agência Nacional de Energia Elétrica (ANEEL), Câmara de Comercialização de Energia Elétrica (CCEE), Comitê de Monitoramento do Setor Elétrico (CMSE) e Operador Nacional do Sistema Elétrico (ONS).

Um dos principais objetivos desse marco regulatório foi promover a modicidade tarifária ${ }^{3}$, que buscava desvincular o preço da energia elétrica do custo marginal de expansão (Siffert Filho et al., 2009). À ANEEL, portanto, cabe estabelecer tarifas que remunerem adequadamente o capital investido pelas empresas, equilibrando os interesses de curto prazo com os de longo prazo, resistindo às pressões dos diversos grupos de interesses (Silva, 2011).

Erber (2014) afirma, no entanto, que, para a modicidade tarifária ser efetiva, ela deve refletir a eficiência da gestão do setor elétrico e que esses níveis tarifários, em vários momentos da história do setor, acabaram por limitar os investimentos e prejudicam o desempenho das empresas.

Dado o cenário do setor elétrico brasileiro e com base nos estudos nacionais e internacionais sobre governança e valor, três hipóteses foram estabelecidas para este estudo: (H1): Não há uma relação entre a qualidade da governança e o valor de mercado das firmas; (H2) Existe uma relação positiva entre a qualidade da governança e o valor de mercado das firmas; (H3) Existe uma relação negativa entre a qualidade da governança e o valor de mercado das firmas.

Conforme Correia (2008), este estudo analisa cinco dimensões de governança apresentadas pela Teoria de Agência e coerentes com o cenário do mercado de capitais brasileiro: (1) composição do conselho de administração; (2) estrutura de propriedade e de controle; (3) compensação aos gestores; (4) proteção aos acionistas minoritários; e (5) transparência das informações publicadas. Estas dimensões são, então, consolidadas em um índice de qualidade da governança por meio da abordagem Análise de Componentes Principais.

Correia (2008) analisou 242 empresas de capital aberto listadas na BM\&FBovespa, no período de 1997 a 2006, para descobrir quais mecanismos de governança provenientes da teoria da agência apresentam maior importância no contexto brasileiro. A autora utilizou a análise de componentes principais (ACP) aliada à análise de regressão de dados em painel, para construir e validar seu índice de governança para as empresas brasileiras.

Agrupando os indicadores nas cinco dimensões consideradas, Correia (2008) constatou que o mecanismo transparência foi o que mais contribuiu para a formação do índice, com uma participação de, aproximadamente, 
$39 \%$; seguido de proteção aos acionistas minoritários, com 35\%, incentivo aos administradores, $18 \%$, conselho de administração, $7 \%$, e estrutura de propriedade e controle em último lugar, com pouco mais de $1 \%$ do peso do índice de governança.

As 12 variáveis de GC propostas neste estudo compõem as cinco dimensões de GC, e foram analisadas como atributos de governança corporativa individual em diversas outras pesquisas, baseadas na literatura nacional e internacional, conforme pode ser observado na Figura 2, da seção 3. Nesse estudo optou-se pela utilização da técnica estatística ACP (Análise de Componentes Principais) com a intenção de reduzir tais variáveis sem, no entanto, perder seu valor informativo, semelhante ao que foi desenvolvido por Nagar e Basu (2002), Correia (2008), Ammann, et al., (2011) e Peixoto (2012). Em seguida, esse índice foi utilizado em modelos de regressões relacionando-o com os indicadores do valor da firma, como Q de Tobin e MBA (marketto-book sobre o ativo).

O ano de 2008 foi escolhido como sendo o início do período amostral, devido ao fato de que, naquele ano, grande parte das empresas do setor elétrico passou a adotar as normas internacionais de contabilidade, ainda que de forma voluntária, tornando os números contábeis mais comparáveis e harmônicos. De acordo com Zonatto, Santos, Rodrigues e Bezerra (2011), neste ano, o nível de adesão voluntária das empresas pertencentes ao segmento de geração e distribuição de energia elétrica foi de $77,1 \%$ para empresas cujo controle era privado e $72,24 \%$ para as controladas pelo poder público.

O artigo está estruturado em cinco seções: além dessa introdução, é feita uma revisão da literatura sobre o tema, na seção 2. Após essa etapa, apresentam-se os aspectos metodológicos na seção 3 . Na seção 4 descrevem-se os resultados. Por fim, na seção 5, algumas considerações e conclusões pertinentes à pesquisa são apresentadas. Propostas para futuras pesquisas são oferecidas na seção final do artigo.

\section{Referencial Teórico}

\subsection{Pressupostos Da Governança Corporativa}

Por ser um constructo multidimensional e de caráter multifacetado, a governança corporativa é formada pela combinação dos diversos mecanismos de controle dos problemas de agência, que busca mitigar os conflitos de interesse entre os atores na organização. Nesse sentido, ela proporciona um alinhamento dos interesses dos administradores aos dos acionistas e desses entre si, de forma a garantir o retorno do investimento aos provedores do capital (Correia, 2008).

Os conflitos surgem na medida em que os acionistas - agentes principais ou outorgantes - têm o seu foco em decisões financeiras, alocação de recursos, maximização do retorno das carteiras e diversificação do risco, enquanto os gestores - agentes executores - são focados em decisões empresariais, conhecimento do negócio, estratégias e operações (Andrade \& Rossetti, 2012).

Para Correia (2008), no Brasil, tais conflitos estão relacionados principalmente à concentração da propriedade acionária em poder de acionistas majoritários, o que resulta essencialmente na violação da regra "uma ação um voto", implicando em diferentes categorias de acionistas, com interesses diferentes. Assim, segundo a autora, para o contexto brasileiro, as principais dimensões da governança corporativa podem ser representadas por: conselho de administração e sua composição, estrutura de propriedade e controle, compensação e incentivos aos gestores, proteção aos acionistas minoritários e transparência das informações publicadas.

O conselho de administração é considerado o principal mecanismo interno de governança corporativa, tendo papel fundamental na diminuição dos custos de agência (Almeida et al. 2013; Gorga, 2005; Silveira, 2006). Duas características dos conselhos devem ser consideradas: o tamanho e a independência.

Salmon (2001) acredita que um conselho com número menor que 8 membros dificulta a formação das comissões internas com a presença de conselheiros externos e, mais de 15 membros dificulta e torna moroso o processo decisório, que quase sempre é extenso e cansativo. O IBGC, por sua vez, delimita entre 5 a 11 o número ideal dos membros do Conselho de Administração, de acordo com o perfil da sociedade. Quanto à composição, existem três classes de conselheiros: i) independentes; ii) externos e, iii) internos (IBGC, 2009).

Para Dutra e Saito (2001), a recomendação do IBGC de que a maioria dos conselheiros seja independente se justifica pelo fato de que estes têm uma visão mais crítica, imparcial e objetiva da atuação dos diretores, de acordo com o interesse dos acionistas. No entanto, essa independência também pode ser um fator restritivo da eficácia dos mesmos, já que estes servem ao conselho apenas em tempo parcial e são alheios ao cotidiano da empresa, dependendo fortemente da gestão executiva para obter informações (Wong, 2009).

Com relação à separação de funções entre presidente do conselho e o CEO (Chief Executive Officer) é recomendável que o CEO, o principal executivo da empresa, participe do conselho de administração apenas como convidado (IBGC, 2009). Portanto, os papéis de presidente do Conselho e presidente da empresa não devem ser exercidos pela mesma pessoa, de forma que não haja concentração de poder nem prejuízo da supervisão da gestão pelo Conselho de Administração. 


\section{Flávia Ferreira Marques Bernardino, Fernanda Maciel Peixoto, Roberto do Nascimento Ferreira}

A política de compensação e incentivos aos gestores, por sua vez, também pode amenizar o problema de agência, motivando os gerentes a otimizar o valor de longo prazo ou os ganhos potenciais da empresa e funcionando como estimuladores que atrelam o comportamento dos administradores aos objetivos dos acionistas (Watts \& Zimmerman, 1986).

As modalidades de compensação aos gestores - salários, bônus, e compensações de longo prazo - têm a finalidade de recompensar e também de punir os gestores em função de seu desempenho e, assim, motivá-los a agir com maior eficiência, alinhados com os interesses dos proprietários (Peixoto, 2012).

Segundo Sonza (2012, p. 51) “altos níveis de compensação são particularmente prejudiciais quando não estão ligados ao desempenho, ou seja, quando os executivos recebem grandes quantidades de dinheiro por resultados insatisfatórios na empresa". No entanto, condicionar a compensação dos gestores apenas ao desempenho requer cautela, dada a dificuldade de mensuração eficiente do desempenho.

Uma alternativa viável é a empresa definir os benefícios implícitos e explícitos que minimizam o problema decorrente da dificuldade dos investidores externos de acompanhar a gestão e a possibilidade de os gestores cometerem atos que impliquem em perda de valor da empresa. Os principais incentivos explícitos são revisão periódica dos salários, os bônus e a utilização de opções. Dentre os incentivos implícitos estão as ameaças de demissão do conselho, em função do desempenho, ameaça de ser substituído em função de uma má performance em uma crise financeira, entre outros (Tirole, 2006).

A compensação baseada em bônus apresenta dois problemas: os planos de bônus são baseados em resultados contábeis, que podem ser manipulados para indicar um bom desempenho; além disso, podem incentivar os executivos a privilegiar ações de curto prazo em detrimento de ações de longo prazo (Sonza, 2012).

A estrutura de propriedade e controle é um importante mecanismo de governança corporativa, que desempenha um papel central na determinação da medida em que os interesses dos proprietários e gestores estão alinhados (Dalton, Daily, Certo \& Roengpitya, 2003).

Apesar de considerarem os benefícios da concentração de propriedade sobre os conflitos de agência entre gestores e acionistas, Shleifer e Vishny (1997) acenam com a possibilidade de haver custos associados à divergência de interesses entre acionistas minoritários e majoritários. Nos países em que a proteção aos acionistas minoritários é fraca, há uma tendência à concentração de propriedade e a uma maior expropriação dos minoritários (Foley \& Greenwood, 2010; Holderness \& Sheehan, 1988; La Porta, Lopez-de-Silanes \& Shleifer, 1999).

Claessens et al. (2002), investigaram a relação entre a concentração de propriedade e o valor da firma. Constataram que o valor da empresa aumenta com a concentração do fluxo de caixa nas mãos do acionista majoritário, em função do efeito incentivo ou efeito alinhamento, e que quando os direitos de controle são maiores que os direitos sobre o fluxo de caixa, a empresa perde valor, devido ao efeito entrincheiramento.

O chamado efeito entrincheiramento, preconizado por Jensen \& Mecking (1976), Morck, et al. (1988) e estudado por Claessens et al. (2002) é uma consequência negativa dessa concentração acionária, uma vez que acaba por acarretar custos de monitoramento para a empresa. Isso ocorre porque os grandes acionistas buscam para si benefícios privados de controle, ou seja, se beneficiam com ganhos extras, além do que seria justo por sua parcela na propriedade, em detrimento dos acionistas minoritários (STULZ,1988).

Por outro lado, o efeito incentivo ou alinhamento configura-se como um benefício da concentração acionária, de forma que, à medida que o número de ações detidas pelo controlador aumenta, ocorre também um aumento do monitoramento das ações dos dirigentes e, portanto, um alinhamento entre objetivos de acionistas e gestores com posições acionárias na firma. No entanto, paralelamente, pode haver aumento nos custos associados à expropriação (Shleifer \& Vishny, 1997

O direito de controle refere-se ao percentual de ações ordinárias nas mãos do acionista majoritário, enquanto o direito sobre o fluxo de caixa representa o percentual de ações ordinárias e preferenciais em poder do controlador (Claessens et al. 2002). Para La Porta et al. (1999), a existência de várias classes de ações promove a segregação entre o direito sobre o fluxo de caixa e o direito de controle nas empresas e, com isso, se provoca o efeito entrincheiramento.

Quanto à proteção aos acionistas minoritários esta é, em grande parte, determinada pelo sistema legal de cada país e pela qualidade de seu enforcement. Quando os direitos dos investidores e dos credores são amplos e bem aplicados pelos órgãos reguladores ou tribunais, os financiadores se sentem mais dispostos a financiar as empresas (La Porta et al. 1998, 2002).

Peixoto (2012) utilizou as seguintes variáveis proxies para o nível de proteção aos acionistas minoritários: a) o fato de as organizações proporcionarem às ações preferenciais direito de voto; b) a prioridade no direito ao reembolso das ações preferenciais, em caso de liquidação, c) a negociação de títulos ADRs (American Depositary Receipts) no mercado de ações norte-americano, e; d) o índice de Payout.

Por fim, tem-se o mecanismo de GC denominado transparência, que se refere à divulgação das informações econômico-financeiras pelas empresas, como forma de promover maior confiabilidade aos investidores. A redução da assimetria da informação, proporcionada pela qualidade das informações financeiras 
publicadas, promove a redução dos conflitos de interesse e, por isso, a transparência das informações publicadas pode ser considerada como um importante mecanismo de governança (Correia, 2008).

Uma das dimensões da transparência pode ser expressa pela adoção do serviço de auditoria independente. Bortolon, Sarlo Neto e Santos (2013) acreditam que a auditoria independente é importante para aumentar a transparência na relação gestor-investidor, uma vez que são os auditores que atestam para os acionistas e os demais stakeholders que os relatórios financeiros da empresa são precisos e verdadeiros.

Segundo Ahmad, Hassan e Mohammad (2003), as principais firmas de auditoria (Deloitte ToucheTohmatsu, Ernest\&Young, KPMG e PriceWaterhouseCoopers), que pertencem ao grupo denominado Big Four, não estão dispostas a se associar com clientes cujos níveis de evidenciação sejam baixos. A seleção de auditores com reputação global (as Big Four) pode, portanto, indicar melhores práticas de divulgação e transparência (Khanchel, 2007).

\subsection{Governança Corporativa e Valor da Firma}

De acordo com Ehikioya (2009), boas práticas de governança corporativa ajudam a empresa a atrair investimentos, captar recursos e fortalecer as bases para melhorar seu valor de mercado. Diversos trabalhos têm relacionado aspectos da governança corporativa com o valor, encontrando uma relação positiva (Correia, 2008; Gompers et al. 2003; Klapper \& Love, 2004; Lameira, 2007; Lameira et al., 2005; Lima, 2009; Macedo \& Corrar, 2009; Silveira et al. 2005).

Gompers et al. (2003) estudaram a proteção do direito dos acionistas das companhias norte-americanas, na década de 90 e sua relação com a rentabilidade e valor de mercado. Descobriram que empresas com maior proteção aos direitos de seus acionistas apresentaram maiores lucros, maior crescimento das vendas e maior valor de mercado, para o período e amostra investigados.

Klapper e Love (2004) utilizaram o índice de governança criado pelo banco Credit Lyonnais Securities Asia (CSLA) para avaliar a relação entre governança e desempenho das empresas em 14 países emergentes. Eles observaram um maior nível de governança corporativa nas companhias que negociavam ADRs nas bolsas norteamericanas e que tais empresas apresentavam maior valor de mercado.

Correia (2008) analisou a relação entre performance contábil, financeira, valor de mercado e um índice de governança elaborado com a técnica Análise de Componentes Principais, para 242 empresas da BM\&FBovespa, no período de 1997 a 2006. A autora obteve relação positiva e significativa entre o índice obtido e o Q de Tobin e também percebeu que no contexto brasileiro os mecanismos de governança corporativa assumem importância distinta.

No entanto, ressalta-se que algumas pesquisas não confirmaram a relação positiva esperada entre GC e valor, ou mesmo indicaram uma relação negativa entre esses aspectos (Almeida et al. 2013; Carvalhal-da-Silva \& Leal, 2005; Cremers \& Ferrell, 2010; Demsetz \& Villalonga, 2001; Ehikioya, 2009; Gotardelo, 2006; Peixoto, 2012).

Demsetz e Vilallonga (2001) buscaram demonstrar a relação entre a estrutura de propriedade e a performance e não encontraram uma associação significativa entre Q de Tobin e governança, quando a endogeneidade foi controlada. Carvalhal-da-Silva e Leal (2005) também não encontraram uma relação estatisticamente significativa entre $Q$ de Tobin e qualidade da governança, medida por um índice criado por eles e aplicado a 131 empresas da BM\&FBovespa, no período de 1998 a 2002.

Gotardelo (2006), em sua pesquisa com 117 empresas listadas na BM\&FBovespa entre 2002 e 2004 concluiu que os resultados encontrados foram diferentes do esperado, uma vez que vários aspectos da governança se comportaram de forma inversa em relação ao valor de mercado.

Cremers e Ferrel (2010) acompanharam as práticas de governança de aproximadamente 1.000 empresas, entre 1978 e 2006, utilizando os índices de Gompers et al. (2003) e Bebchuck et al. (2009) e buscando sua relação com o valor das empresas. Constataram associação negativa robusta entre os índices de governança usados e o Q de Tobin, para o período analisado.

Peixoto (2012) analisou a relação entre governança e desempenho/valor/risco de empresas brasileiras de capital aberto em períodos de crise e de não crise no intervalo de 2000 a 2009. A autora definiu como crise geral o período de 2000 a 2002, não-crise o período de 2003 a 2007, e crise financeira global a ocorrida em 2008. O termo "não-crise" foi adotado para o período em que não houve crises internas e/ou externas que exerceram impactos sobre a economia e o mercado de capitais brasileiro.

Quando Peixoto (2012) relacionou o Q de Tobin com índices de GC calculados, estes revelaram-se negativamente associados com o valor em períodos de não-crise, contrariando uma das hipóteses levantadas pela autora, de que quanto maior o nível de governança maior o valor de mercado. O mesmo resultado foi obtido com relação aos indicadores MBPL (market-to-book considerando o valor patrimonial das ações) e MBA (market-to-book considerando o valor contábil do ativo) os quais são proxy de valor de mercado e também retornaram uma associação negativa significativa com a qualidade da governança, em períodos de não-crise. 


\section{Flávia Ferreira Marques Bernardino, Fernanda Maciel Peixoto, Roberto do Nascimento Ferreira}

No entanto, Peixoto (2012) constatou que, em períodos de instabilidade econômica, como, por exemplo, a crise do subprime americano de 2008, empresas bem governadas apresentam maior valor de mercado, conforme aponta a literatura. Isto é, os mecanismos de governança corporativa assumem importâncias distintas em momentos de crise e de não-crise.

Outros estudos apontam que empresas com melhores práticas de governança apresentam menor volatilidade em seus retornos em períodos de crise econômica, quando comparadas com companhias que proporcionam menor proteção aos acionistas (Johnson, Boone, Breach, \& Friedman, 2000; Lemmon \& Lins, 2001; Srour, 2005; Fischer, 2012).

Liu, Uchida e Yang (2012) investigaram a relação entre governança corporativa e valor da firma na China durante a crise financeira de 2008. Como resultados observaram que: as empresas com controle governamental apresentaram desempenho melhor durante a crise; que nessas empresas a propriedade gerencial é associada positivamente à performance durante a crise e que as empresas chinesas que contrataram firmas de auditoria de reputação global experimentaram menor redução no valor da firma durante a crise de 2008.

\section{Aspectos Metodológicos}

Realizou-se uma pesquisa quantitativa, de natureza aplicada utilizando técnicas estatísticas, correlacionando as variáveis e verificando o impacto e a validade da pesquisa (Martins \& Theóphilo, 2007). A amostra foi constituída por 55 empresas pertencentes ao setor elétrico brasileiro, listadas na BM\&FBovespa, no período de 2008 a 2012. A descrição das empresas que compõem a amostra encontra-se na Figura 1.

\begin{tabular}{|c|c|c|c|}
\hline Nome da Empresa & Segmento & Nome da Empresa & Segmento \\
\hline AES Elpa S/A & Holding & CPFL Energias Renováveis S/A & Geração \\
\hline AES Sul Distribuidora Gaúcha de Energia S/A & Distribuição & Elektro - Eletricidade e Serviços & Distribuição \\
\hline AES Tiete S/A & Geração & Eletrobras - Centrais Elétricas do Brasil S/A & $\begin{array}{l}\text { Distribuição } \\
\text { /Transm }\end{array}$ \\
\hline Afluente Geração de Energia Elétrica S/A & Geração & Eletropar - Eletrobrás Participaçoes S/A & Holding \\
\hline Andrade Gutierrez Concessões S/A & Holding & $\begin{array}{l}\text { Eletropaulo Metropolitana Eletricidade de São } \\
\text { Paulo S/A }\end{array}$ & Distribuição \\
\hline Alupar Investimentos S/A & Holding & $\begin{array}{l}\text { Emae - Empresa Metropolitana Aguas Energia } \\
\text { S/A }\end{array}$ & Geração \\
\hline Ampla Energia e Serviços & Distribuição & Energias BR - Energias do Brasil S/A & $\begin{array}{l}\text { Gera / Distrib / } \\
\text { Com }\end{array}$ \\
\hline Bandeirante Energia S/A & Distribuição & Energisa S/A & Holding \\
\hline Ceb-Cia Energética de Brasília & Distribuição & $\begin{array}{l}\text { Enersul - Empresa Energética de Mato Grosso do } \\
\text { Sul S/A }\end{array}$ & Distribuição \\
\hline $\begin{array}{l}\text { Ceee-D Cia Estadual de Distribuição de } \\
\text { Energia Elétrica }\end{array}$ & Distribuição & Equatorial Energia S/A & Holding \\
\hline $\begin{array}{l}\text { Ceee-Gt Cia Estadual de Geração e } \\
\text { Transmissão de Energia Elétrica }\end{array}$ & $\begin{array}{l}\text { Geração / } \\
\text { Transmissão }\end{array}$ & Escelsa - Espírito Santo Centrais Elétricas S/A & Distribuição \\
\hline Celesc - Centrais Elétricas de Santa Catarina & Distribuição & $\begin{array}{l}\text { Ger Paranap - Duke Energy Geração } \\
\text { Paranapanema S/A }\end{array}$ & Geração \\
\hline Celgpar - Cia Celg de Participações & Holding & Investco S/A & Geração \\
\hline Celpa - Centrais Elétricas do Pará S/A & Distribuição & Itapebi Geração de Energia S/A & Geração \\
\hline Celpe - Cia Energética de Pernambuco & Distribuição & Light Sesa - Light Serviços de Eletricidade S/A & Distribuição \\
\hline Cemar - Cia Energética do Maranhão & Distribuição & Light S/A & Holding \\
\hline $\begin{array}{l}\text { Cemat - Centrais Elétricas Matogrossenses } \\
\text { S/A }\end{array}$ & Distribuição & MPX Energia S/A & Geração \\
\hline Cemig - Cia Energética de Minas Gerais & Holding & Neoenergia S/A & Holding \\
\hline Cemig Distribuição S/A & Distribuição & Cia Paulista de Força e Luz & Distribuição \\
\hline Cemig Geração e Transmissão S/A & Geração & Proman - Produtores Energéticos de Manso S/A & Geração \\
\hline Cesp - Cia Energética de São Paulo & $\begin{array}{l}\text { Geração / } \\
\text { Comerc }\end{array}$ & Rede Energia S/A & Holding \\
\hline Coelba - Cia Eletricidade do Estado da Bahia & Distribuição & Renova Energia S/A & Geração \\
\hline Coelce - Cia Energética do Ceará & Distribuição & Rio Grande Energia S/A & Distribuição \\
\hline Copel - Cia Paranaense de Energia & Distribuição & $\begin{array}{l}\text { Taesa - Transmissora Aliança de Energia Elétrica } \\
\text { S/A }\end{array}$ & Transmissão \\
\hline $\begin{array}{l}\text { Cosern - Cia Energética do Rio Grande do } \\
\text { Norte }\end{array}$ & Distribuição & Termopernambuco S/A & Geração \\
\hline CPFL Energia S/A & Holding & Tractebel Energia S/A & Geração / Comerc \\
\hline CPFL Geração de Energia S/A & Geração & $\begin{array}{l}\text { Tran Paulist - Cia de Transmissão de Energia } \\
\text { Elétrica Paulista }\end{array}$ & Transmissão \\
\hline $\begin{array}{l}\text { CPFL Piratininga - Cia Piratininga de Força e } \\
\text { Luz }\end{array}$ & Distribuição & & \\
\hline
\end{tabular}

Figura 1. Relação das empresas do setor elétrico, selecionadas para a amostra do estudo

Fonte: BM\&FBovespa, (2013).

No que tange à coleta de dados, este estudo utilizou dados secundários, coletados de diversas fontes, a saber: base de dados Economática; BM\&FBovespa; demonstração das Informações Anuais (IANs) das empresas, entregues à Comissão de Valores Mobiliários (CVM) a cada ano; sítios das empresas da amostra e Revista Exame. 
Foram utilizados os seguintes softwares para a estimação dos modelos de regressão - STATA SE ${ }^{\circledR}$ 11.0, e SPSS 13.0. A metodologia dessa investigação envolveu duas etapas principais.

$\mathrm{Na}$ etapa 1 construiu-se um índice de qualidade da governança, obtido por meio da abordagem $\mathrm{ACP}$ (Análise dos Componentes Principais), semelhante ao que foi desenvolvido por Correia (2008) e Peixoto (2012). A ACP é um método estatístico que reduz um grande número de variáveis correlacionadas entre si a um número menor, realizando combinações lineares ortogonais de modo a reproduzir ao máximo a variância original. Essa técnica decompõe uma matriz com $X$ dados e com $\mathbf{N}$ observações de $K$ indicadores em um novo grupo de $K$ variáveis ortogonais, de forma que a primeira das variáveis apresente a maior variância possível (Nagar \& Basu, 2002).

Foram calculados três índices da qualidade da governança. Um dos índices calculados levou em consideração todas as variáveis utilizadas na ACP. Como a pesquisa utilizou 12 variáveis representativas da governança obteve-se um índice formado pelos 12 componentes principais (IGC12). O segundo índice foi formado apenas pelos componentes que apresentaram autovalores superiores a 1, ou seja, que apresentavam maior poder explicativo da variância dos dados (IGCN). Além destes calculou-se ainda o indicador obtido apenas com a primeira componente no método ACP, ou seja, aquela que explica a maior parcela da variância (IGC1).

\begin{tabular}{|c|c|c|c|}
\hline Variáveis & Fundamentação Teórica & Fórmula & Fonte \\
\hline DCONT & $\begin{array}{l}\text { Bohren \& Odegaard (2004), Lameira (2007), } \\
\text { Ehikioya (2009), Peixoto (2012) e Ferreira (2012). }\end{array}$ & $\begin{array}{l}\text { № ações ordinárias nas mãos do } \\
\text { controlador/ total ações ordinárias }\end{array}$ & CVM/BM\&FBovespa \\
\hline DSFC & $\begin{array}{l}\text { Silveira (2004), Lameira (2007), Correia (2008), } \\
\text { Peixoto (2012) e Ferreira (2012). }\end{array}$ & $\begin{array}{l}\text { № de ações totais nas mãos do } \\
\text { controlador / Total de ações da } \\
\text { empresa }\end{array}$ & CVM/BM\&FBovespa \\
\hline GICA & $\begin{array}{l}\text { Silveira (2004), Correia (2008), Velasquez (2008), } \\
\text { Ehikioya (2009), Peixoto (2012), Ferreira (2012). }\end{array}$ & $\begin{array}{l}\text { № de conselheiros independentes / } \\
\text { no total de conselheiros }\end{array}$ & CVM/BM\&FBovespa \\
\hline SEP_PCEO & $\begin{array}{l}\text { Silveira (2004), Bhagat \& Bolton (2008), Correia } \\
\text { (2008), Ehikioya (2009), Peixoto (2012), Ferreira } \\
(2012) \text {. }\end{array}$ & $\begin{array}{l}0 \text { - se não há separação de funções } \\
\text { entre presidente do conselho e CEO. } \\
1 \text { - se há separação de funções } \\
\text { entre eles. }\end{array}$ & CVM/BM\&FBovespa \\
\hline PART_RES & Correia (2008) e Peixoto (2012). & $\begin{array}{l}0 \text { - se os gestores não participam } \\
\text { dos resultados; } \\
1 \text { - se os gestores participam dos } \\
\text { resultados; }\end{array}$ & CVM/BM\&FBovespa \\
\hline REM_TOT & $\begin{array}{l}\text { Correia (2008), Barontini \& Bozzi (2011) e Peixoto } \\
(2012)\end{array}$ & $\begin{array}{l}\text { Valor absoluto da remuneração paga } \\
\text { aos administradores. }\end{array}$ & CVM/BM\&FBovespa \\
\hline STK_OP & $\begin{array}{l}\text { Correia (2008), Fahlenbrach \& Stulz } \\
\text { (2009), Sonza (2012) e Peixoto (2012) }\end{array}$ & $\begin{array}{l}0 \text { - se não há remuneração baseada } \\
\text { em ações; } \\
1 \text { - se há remuneração baseada em } \\
\text { ações; }\end{array}$ & CVM/BM\&FBovespa \\
\hline PAYOUT & $\begin{array}{l}\text { La Porta et al. (2002); Silveira (2004), Carvalhal-da- } \\
\text { Silva (2004), Srour (2005), e Peixoto (2012) }\end{array}$ & $\begin{array}{l}\text { Payout = Dividendos por ação/Lucro } \\
\text { por ação }\end{array}$ & Economática \\
\hline$\overline{\mathrm{ADR}}$ & $\begin{array}{l}\text { Klapper \& Love (2004), Durnev \& Kim (2005), } \\
\text { Lameira (2007), Correia (2008), e Peixoto (2012) }\end{array}$ & $\begin{array}{l}0 \text { - se não emitieADRs nos níveis II } \\
\text { ou II!; } \\
1 \text { - se emite ADRs nos níveis II ou III. }\end{array}$ & $\begin{array}{l}\text { BNY Mellon, disponível em } \\
\text { http://www.adrbnymellon.co } \\
\text { m/dr country profile.jsp?cou } \\
\text { ntry=BR\&start=50\&starttopr } \\
\text { ev }=0\end{array}$ \\
\hline AUD_GLOB & $\begin{array}{l}\text { Carvalhal-da-Silva \& Leal (2005), Almeida et al. } \\
(2010), \text { Rover, Tomazzia \& Murcia (2012) }\end{array}$ & $\begin{array}{l}0 \text { - se não contratou Big Four } \\
1 \text { - se contratou Big Four }\end{array}$ & CVM/BM\&FBovespa \\
\hline PRC & Correia (2008) e Peixoto (2012) & $\begin{array}{l}\text { 0 - Quando a empresa tem ações } \\
\text { preferenciais e não há prioridade no } \\
\text { reembolso para elas; } \\
1 \text { - Quando a empresa tem ações } \\
\text { preferenciais e há prioridade no } \\
\text { reembolso para elas; } \\
2 \text { - Quando a empresa não possui } \\
\text { ações preferenciais, somente } \\
\text { ordinárias. }\end{array}$ & CVM/BM\&FBovespa \\
\hline DV_AP & Correia (2008) e Peixoto (2012) & $\begin{array}{l}\text { 0 - Quando a empresa tem ações } \\
\text { preferenciais e não concede algum } \\
\text { direito de votos a elas; } \\
1 \text { - Quando a empresa tem ações } \\
\text { preferenciais e concede algum } \\
\text { direito de votos a elas; } \\
2 \text { - Quando a empresa não possui } \\
\text { ações preferenciais. }\end{array}$ & CVM/BM\&FBovespa \\
\hline
\end{tabular}

Figura 2. Variáveis usadas na construção dos índices de GC Fonte: Elaborado pelos autores.

Para representar os mecanismos de governança corporativa utilizaram-se as seguintes variáveis, fundamentadas na literatura sobre o tema: direito de controle (DCONT), direito sobre o fluxo de caixa (DSFC), separação entre presidente do conselho de administração e o CEO (SEP_PCEO), grau de independência do conselho de administração (GICA), índice de payout (PAYOUT), direito de vōto das ações preferenciais (DV_AP), emissão de ADRs (ADR), prioridade no reembolso do capital em caso de liquidação (PRC), remuneração total dos administradores (REM_TOT), participação dos administradores nos resultados da empresa (PART_RES), plano de opções para exečutivos (STK_OP) e auditoria global (AUD_GLOB). Além disso, adotaram-se alḡumas 
variáveis de controle, tais como: tamanho da empresa e adesão aos níveis de governança da BM\&FBovespa, na intenção de abranger outros aspectos que também poderiam influenciar o valor da firma. As variáveis representativas da GC utilizadas na construção dos índices estão detalhadas na Figura 2.

$\mathrm{Na}$ etapa 2, foram estimados modelos de regressão com dados em painel para verificar uma possível relação entre o índice de GC obtido na etapa 1 e indicadores de valor de mercado como Q de Tobin e MBA (índice market-to-book). A especificação do modelo utilizado pode ser descrita conforme Equação 1:

$$
\text { VarValor } i=\beta_{1} * \text { IGC }+\beta_{2} * \text { VarCont }+\varepsilon i \quad \text { Eq. (1) }
$$

Onde:

VarValori = Variáveis de valor de Mercado (Q de Tobin e MBA alternados)

IGC = índices de governança corporativa calculados (alternando IGC12, IGCN e IGC1)

VarCont = variáveis de controle: adesão aos NDGC da bolsa, alavancagem financeira, crescimento das receitas, $\mathrm{ROE}$ e liquidez em bolsa.

Ressalta-se que a escolha das variáveis de controle se baseou na literatura sobre o tema, especialmente em Correia (2008) e Peixoto (2012), as quais foram extraídas da base de dados Economática e da BM\&FBovespa.

\section{Apresentação e Análise dos Resultados}

A Tabela 1 traz uma descrição comparativa dos índices de governança obtidos, considerando todo o período amostral e o agrupamento com relação aos NDGC da BM\&FBovespa.

\section{Tabela 1}

Descrição comparativa dos índices de governança corporativa da amostra

\begin{tabular}{l|ccc|ccc|ccc}
\hline & \multicolumn{3}{|c|}{ Todas as Empresas } & \multicolumn{3}{c|}{ Empresas com NDGC } & \multicolumn{3}{c}{ Empresas Outros Segm. } \\
\hline & IGC1 & IGC12 & IGCN & IGC1 & IGC12 & IGCN & IGC1 & IGC12 & IGCN \\
\hline Média & 0.48 & 0.50 & 0.42 & 0.63 & 0.60 & 0.59 & 0.41 & 0.45 & 0.35 \\
Desv_Pad & 0.25 & 0.23 & 0.25 & 0.24 & 0.26 & 0.28 & 0.22 & 0.21 & 0.19 \\
Mínimo & 0 & 0 & 0 & 0 & 0 & 0 & 0 & 0 & 0 \\
Máximo & 1 & 1 & 1 & 1 & 1 & 1 & 1 & 1 & 1 \\
\hline
\end{tabular}

Fonte: Resultados da pesquisa.

Todos os índices de governança apresentaram distribuição normal, de acordo com o teste de KolmogorovSmirnov (valor de $p>0,01$ ). O maior índice foi o IGC12 com média de 0,50 e o menor índice foi o IGCN, com média de 0,42 . Para todos os índices calculados há registros de empresas cujos índices foram zero e outras com índices máximos, ou seja, equivalentes a 1 . Comparando o grupo das empresas pertencentes aos NDGC com aquelas pertencentes aos demais segmentos, nota-se que as empresas daquele grupo têm médias superiores a este, para os três índices calculados. Os resultados do teste T de Student confirmaram que as diferenças de médias entre os grupos foram significativas.

Semelhante ao realizado por Correia (2008) e Peixoto (2012), buscou-se associar as médias dos índices de governança com a identidade do controlador (Tabela 2).

Tabela 2

Descrição do IGC12 considerando a identidade do controlador

\begin{tabular}{clccccc}
\hline Tipo & \multicolumn{1}{c}{ Controlador } & N & Média & Desv_Pad & Min & Max \\
\hline 1 & Indivíduos ou famílias & 15 & 0.59 & 0.21 & 0.28 & 1 \\
2 & Investidores institucionais & 5 & 0.84 & 0.05 & 0.79 & 0.90 \\
3 & Estrangeiros & 78 & 0.55 & 0.20 & 0.14 & 1.00 \\
4 & Empresas privadas nacionais & 107 & 0.45 & 0.21 & 0 & 1 \\
5 & Governo & 65 & 0.44 & 0.26 & 0 & 1 \\
6 & Maior acionista não controla & 5 & 0.88 & 0.10 & 0.75 & 0.99 \\
\hline
\end{tabular}

Fonte: Resultados da pesquisa.

Para o IGC12, pode-se inferir que as empresas com maior média no índice $(0,88)$ são aquelas em que o maior acionista não tem o controle, ou seja, o controle é pulverizado. Na sequência estão as empresas cujos 
controladores são os investidores institucionais. As empresas controladas pelo governo foram as responsáveis pela menor média do índice (Tabela 2).

Tabela 3

Descrição do IGC1 considerando a identidade do controlador

\begin{tabular}{clccccc}
\hline Tipo & \multicolumn{1}{c}{ Controlador } & $\mathrm{N}$ & Média & Desv_Pad & Min & Max \\
\hline 1 & Indivíduos ou famílias & 15 & 0.60 & 0.18 & 0.35 & 1 \\
2 & Investidores institucionais & 5 & 0.73 & 0.19 & 0.42 & 0.93 \\
3 & Estrangeiros & 78 & 0.53 & 0.21 & 0.09 & 0.92 \\
4 & Empresas privadas nacionais & 107 & 0.41 & 0.24 & 0 & 1 \\
5 & Governo & 65 & 0.49 & 0.30 & 0 & 1 \\
6 & Maior acionista não controla & 5 & 0.54 & 0.12 & 0.33 & 0.64 \\
\hline
\end{tabular}

Fonte: Resultados da pesquisa.

Classificando o IGC1 de acordo com a identidade do controlador (Tabela 3) percebe-se que as empresas controladas por investidores institucionais são aquelas com maiores índices de governança $(0,73)$ e as que apresentaram a média mais baixa foram as empresas privadas nacionais $(0,41)$. A maior variabilidade $(0,30)$ acontece nas empresas controladas pelo governo (Tabela 3).

Na Tabela 4 pode-se observar que a maior média do IGCN $(0,93)$ se refere às empresas controladas pelos investidores institucionais, consoante ao encontrado no IGC1. Corroborando o resultado encontrado no IGC1, a menor média $(0,35)$ fica por conta das empresas privadas nacionais (Tabela 4$)$.

Tabela 4

Descrição do IGCN considerando a identidade do controlador

\begin{tabular}{clccccc} 
Tipo & \multicolumn{1}{c}{ Controlador } & $\mathrm{N}$ & Média & Desv_Pad & Min & Max \\
\hline 1 & Indivíduos ou famílias & 15 & 0.57 & 0.30 & 0.07 & 1 \\
2 & Investidores institucionais & 5 & 0.93 & 0.09 & 0.78 & 1.00 \\
3 & Estrangeiros & 78 & 0.47 & 0.21 & 0.10 & 0.97 \\
4 & Empresas privadas nacionais & 107 & 0.35 & 0.21 & 0 & 1 \\
5 & Governo & 65 & 0.39 & 0.26 & 0 & 1 \\
6 & Maior acionista não controla & 5 & 0.76 & 0.15 & 0.62 & 1.00 \\
\hline
\end{tabular}

Fonte: Resultados da pesquisa.

Comparando com os resultados obtidos por Correia (2008) e Peixoto (2012) para o relacionamento dos índices com o tipo de controlador, constatou-se que empresas controladas por investidores institucionais apresentam melhores níveis de governança, corroborando a pesquisa das autoras. Quanto às menores médias, os resultados obtidos para os índices IGC1 e IGCN concordam com os resultados de Correia (2008) indicando que as empresas privadas nacionais apresentam as médias mais baixas e contraria o resultado de Peixoto (2012) onde as empresas familiares eram responsáveis pela menor média nos três índices.

Na sequência serão expostos os resultados da análise de regressão dos modelos estimados e dos testes de diagnóstico utilizados: teste de Hausman, teste de heterocedasticidade de Baum (2001) e teste de autocorrelação de Wooldridge (2002). Além disso, serão apresentadas as constatações empíricas mais importantes.

Para garantir que os resultados fossem robustos foram calculadas três regressões para cada índice de governança, inserindo diferentes variáveis de controle nos modelos. Em todos os modelos as variáveis independentes foram ora o IGC12, ora o IGCN. Os testes efetuados com o IGC1 não mostraram significância estatística, por isso foram omitidos nessa etapa.

As variáveis de controle selecionadas neste estudo foram proxies de: alavancagem financeira (af), tamanho da empresa, representado pelo crescimento da receita (cresc_rec), rentabilidade do patrimônio líquido (ROE) e liquidez em bolsa (liqbol), além das variáveis indicativas do nível de adesão aos NDGC da bolsa (ades). A seleção das variáveis de controle se baseou nos trabalhos de Correia (2008) e Peixoto (2012).

Apresentam-se na tabela 5 os resultados dos modelos que estimaram a relação entre a qualidade da governança e o valor de mercado das empresas, medido pelo Q de Tobin. Nesses modelos as variáveis de controle foram: af, cresc_rec, roe, liqbol e ades.

Para todas as especificações, os resultados dos testes de efeitos individuais revelaram-se significativos, isto é, não se pode aplicar o método MQO (Mínimos Quadrados Ordinários). Foi detectada heterocedasticidade 
nos dados, no entanto, não foi observada presença de autocorrelação em nenhum dos modelos. Portanto, os modelos foram estimados sob a forma de painel, com correção robust para a matriz de covariância dos coeficientes.

Os resultados do Teste de Hausman apontaram a preferência pelo modelo de efeitos aleatórios. Em ambos os modelos (IGC12 e IGCN) que associaram os índices de governança ao valor de mercado das empresas (Q de Tobin) observa-se uma relação negativa e significativa, contrariando as evidências empíricas sobre o tema encontradas por Carvalhal-da-Silva e Leal (2005) e Correia (2008), conforme Tabela 5. Esse resultado, no entanto, corrobora o encontrado por Peixoto (2012) nos momentos de não-crise, inclusive com relação ao comportamento da variável proxy do tamanho da empresa (crescimento da receita), que também indicou um relacionamento negativo com o Q de Tobin.

Tabela 5

Associação entre os índices de governança e Q de Tobin

\begin{tabular}{lcc}
\hline Variável & Q_tobin (1) & Q_tobin (2) \\
\hline igc12 & $-2.2 * *$ & -0.34 \\
Af & -0.5 & $-2.25^{* *}$ \\
cresc_rec & $-2.71 * * *$ & 0.58 \\
Roe & 0.26 & 0.03 \\
Liqbol & 0.49 & $-3.66^{* * *}$ \\
ades1 & $-3.92^{* * *}$ & 0.15 \\
ades2 & 0.12 & 1.19 \\
ades3 & 1.12 & $-1.87 *$ \\
Igcn & & $8.09 * * *$ \\
Constante & $7.7 * * *$ & $1 \mathrm{GCN}$ \\
\hline Testes de Diagnóstico & $1 \mathrm{GC12}$ & 0.1705 \\
Teste de Hausman (valor $p)$ & 0.2011 & 0.0000 \\
Teste de Heteroc. de Baum (2001) & 0.0000 & 0.1138 \\
\hline Teste de Autocorr. de Wooldridge (2002) & 0.1572 &
\end{tabular}

Fonte: Resultados da pesquisa.

A variável ades1 também se comporta em sentido oposto ao $Q$ de Tobin, ou seja, com sinal negativo e significativo, corroborando o comportamento dos índices, já que são proxies do mesmo constructo. Por sua vez, as variáveis referentes à adesão ao nível 2 e Novo Mercado, liquidez em bolsa e retorno sobre o patrimônio líquido se comportaram de forma positiva porém, não foram estatisticamente significativas.

Tabela 6

Associação entre os índices de governança e MBA

\begin{tabular}{lcc}
\hline Variável & MBA (1) & MBA (2) \\
\hline igc12 & $-1.9 *$ & 1.42 \\
af & 1.08 & 0.83 \\
cresc_rec & 1.06 & 1.48 \\
Roe & 1.13 & -0.09 \\
Liqbol & $2.51 * *$ & $-1.83^{*}$ \\
ades1 & 0.64 & $-2.85^{* * *}$ \\
ades2 & Omitida & 1.07 \\
ades3 & $52.78^{* * *}$ & $-1.70^{*}$ \\
Igcn & & $5.18^{* * *}$ \\
Constante & $8.94 * * *$ & $1 \mathrm{GCN}$ \\
\hline Testes de Diagnóstico & $1 \mathrm{GC12}$ & 0.7955 \\
Teste de Hausman (valor p) & 0.0000 & 0.0000 \\
Teste de Heteroc. de Baum (2001) & 0.0000 & 0.1218 \\
Teste de Autocorr. de Wooldridge (2002) & 0.1789 & \\
\hline
\end{tabular}

Fonte: Resultados da pesquisa.

Na Tabela 6 estão os resultados dos modelos que relacionaram os índices de governança e o índice market-to-book/AT, utilizado como proxy do valor de mercado das empresas. O modelo para IGC12 foi estimado 
pelo método dos efeitos fixos, enquanto o modelo para IGCN pelo método dos efeitos aleatórios, conforme apontou o Teste de Hausman.

Como não ficou evidenciada a presença de autocorrelação para nenhum dos dois modelos, eles foram estimados apenas com correção robust de heterocedasticidade na matriz de covariância dos coeficientes.

Os resultados para ambos os modelos revelaram uma relação inversa entre governança e valor de mercado, uma vez que os coeficientes dos índices de qualidade da governança se mostraram negativos e significativos. Esse resultado confirmou o resultado encontrado para a variável Q de Tobin que também funciona como proxy do valor de mercado das empresas, corroborando os resultados de Peixoto (2012), para os momentos de não-crise.

Com relação às variáveis de controle, os comportamentos foram distintos para os dois modelos. No modelo com IGC12, a liquidez em bolsa e a adesão ao novo mercado impactaram de forma positiva e significativa no valor de mercado das empresas. No que se refere ao modelo que estimou a relação com o IGCN, percebe-se uma relação inversa e significativa entre a adesão aos níveis 1 e 2 de GC e valor de mercado dessas empresas. Importante ressaltar que Peixoto (2012) também encontrou associações semelhantes para as variáveis de controle.

\section{Considerações Finais}

O objetivo principal desse estudo foi analisar os efeitos da adoção de mecanismos de governança corporativa pelas empresas de capital aberto do setor elétrico brasileiro sobre seu valor de mercado, no período de 2008 a 2012. Para tanto foi construído um índice que mede a qualidade da governança, o qual foi utilizado nos modelos de regressão de dados em painel no intuito de se obter uma possível relação entre ele e os indicadores de valor de mercado Q de Tobin e MBA (market-to-book considerando o valor contábil do ativo).

Foram elaborados três índices de qualidade da GC, conforme as modalidades de Análise de Componentes Principais, resultando no IGC1, IGCN e IGC12. O resultado da estatística descritiva para os índices construídos indicou que no setor elétrico o índice médio de governança é de aproximadamente 0.50, corroborando o resultado encontrado por Peixoto (2012) para o mesmo setor. As empresas que estão listadas em algum dos NDGC da bolsa apresentaram valores maiores para os três índices, o que era esperado.

Realizou-se ainda uma descrição dos índices relacionando-os com a identidade do controlador e observou-se que no caso do IGC12, nas empresas cujo controle é pulverizado, os índices de governança são mais elevados. Os demais índices se apresentaram mais elevados no grupo de empresas controlados pelos investidores institucionais.

Com relação aos resultados da análise de regressão com dados em painel, pôde-se perceber que nos modelos que associaram os índices de governança com valor de mercado, medido pelo Q de Tobin, obteve-se uma relação negativa e significativa entre esses aspectos, corroborando o resultado encontrado por Peixoto (2012) para os momentos de não-crise, inclusive com relação ao comportamento da variável proxy do tamanho da empresa (cresc_rec).

Conclusão semelhante foi encontrada com relação à variável market-to-book/ativo total, confirmando o resultado encontrado no relacionamento com Q de Tobin e os resultados de Peixoto (2012) para os momentos de não-crise ou estabilidade econômica.

Diante de tais considerações, pode-se afirmar que, no geral, esta pesquisa constatou que há uma relação negativa e estatisticamente significativa entre qualidade da governança e valor de mercado (medido por Q de Tobin e MBA), contrariando parte da literatura sobre o tema (Carvalhal-da-Silva \& Leal, 2005; Correia, 2008; Silveira, 2004), mas corroborando o estudo de Cremers e Ferrel (2010) e Peixoto (2012) em momentos de nãocrise.

Infere-se que a relação negativa encontrada entre governança e valor de mercado pode estar ligada às particularidades do setor elétrico, como por exemplo, o fato de ser um setor altamente regulado pelo governo e pela presença expressiva de holdings, ou mesmo ao fato de o mercado de capitais brasileiro ser pouco desenvolvido, ou devido ao reduzido nível de liquidez das empresas, o que segundo Zheka (2005) e Destefanis e Sena (2007) afetaria o comportamento dos indicadores de valor da firma.

Ao avaliar o cenário e as práticas do mercado de ações no Brasil, observa-se que o mercado de capitais percebe rapidamente o risco regulatório das mudanças na legislação. A Medida Provisória 579, posteriormente transformada na Lei $12.873 / 2013$, impôs mudanças significativas nas tarifas dos ativos mais antigos de geração e transmissão que tiveram seus contratos renovados e alterou a relação intramercados de energia elétrica no Brasil (Castro, Brandão, Dantas \& Rosental, 2013).

Para Castro et al. (2013), o impacto financeiro da regulação citada sobre as empresas de geração e transmissão de energia elétrica redundou em baixas significativas na cotação das ações das empresas afetadas na bolsa de valores. De acordo com os citados autores, as ações da Eletrobrás perderam metade do valor (baixa de 49,7\%), enquanto as ações da CESP caíram $40 \%$ e as da CEMIG 33\%, ao longo de 2013 . Este fato poderia explicar parcialmente os resultados deste estudo, que encontrou relação negativa entre GC e valor das empresas do setor elétrico no período de 2008 a 2012. Ressalta-se que a maior contribuição deste estudo é o 
tratamento da qualidade da governança corporativa por meio da técnica ACP, que considera os aspectos multidimensionais e altamente correlacionados da governança entre si, e o desenvolvimento de um índice consolidado para medir a GC das firmas. Sabe-se que são poucos os trabalhos no Brasil e no exterior que trataram a governança dessa forma (Correia, 2008; Peixoto, 2012) em comparação a estudos que mensuram a GC por meio de questionários com respostas objetivas do tipo "sim" ou "não", visando criar índices de GC (Carvalhal-da-Silva \& Leal, 2005; Lameira, 2007, Mello, 2007). Infere-se que o uso de técnicas estatísticas avançadas seja mais adequado para medir a qualidade da GC, consolidando suas múltiplas dimensões apresentadas pela Teoria de Agência, ao invés do uso de questionários sujeitos a vieses conforme a escolha de perguntas subjetivas e discricionárias ao gestor/respondente.

Para estudos futuros, sugere-se a utilização de uma amostra maior, de forma que os resultados sejam mais robustos, ou mesmo comparações entre diversos países. Também poderia ser analisado um período maior, levando em consideração os efeitos do cenário macroeconômico, como por exemplo, períodos de crises, que podem influenciar o desempenho das firmas. Recomenda-se também avaliar outras variáveis ou dimensões de GC e outras medidas de valor da firma e/ou desempenho financeiro.

\section{Notas}

1. Agradecemos pelas valiosas contribuições dos avaliadores da revista, pelo precioso trabalho de revisão realizado no artigo, promovendo o engrandecimento da pesquisa.

2. Conforme o estudo de Shleifer e Vishny (1997), que trata da governança sob a perspectiva da Teoria da Agência.

3. Mecanismo de contratação de energia por meio de leilões na modalidade "menor tarifa", por meio de licitação conjunta dos distribuidores (pool) visando: economias de escala na contratação, dividir os riscos e benefícios contratuais e equalizar as tarifas de suprimento. Além disso, a modicidade tarifária buscava também contratar separadamente, via licitação, energia de usinas novas e usinas já existentes, para suprir a expansão da demanda (Amaral Filho, 2007).

\section{Referências}

Ahmad, Z., Hassan, S., \& Mohammad, J. (2003). Determinants of environmental reporting in Malaysia. International journal of Business Studies, 11(1), 69-90.

Almeida, M. A., Santos, J. F dos., Ferreira, L. F. V. de M., \& Torres, F. J. V. (2010). Evolução da Qualidade das Práticas de Governança Corporativa: um Estudo das Empresas Brasileiras de Capital Aberto Não Listadas em Bolsa. RAC, 14(5), 907-924.

Almeida, R. S. de., Klotzle, M. C., Pinto, A. C. F. Composição do conselho de Administração no setor de energia elétrica do Brasil. Revista de Administração da UNIMEP, 11(1), 156-180.

Amaral Filho, J. B. de S. A reforma do setor elétrico brasileiro e a questão da modicidade das tarifas. $231 \mathrm{f}$. Tese (Doutorado em Ciências Econômicas) - Instituto de Economia da UNICAMP, São Paulo, SP, Brasil.

Ammann, M., Oesch, D., \& Schmid, M. M. (2011). Corporate governance and firm value: International evidence. Journal of Empirical Finance. 18, 36-55.

Andrade, A., \& Rossetti, J. P. (2012) Governança corporativa: fundamentos, desenvolvimento e tendências. São Paulo: Atlas.

Barontini, R., \& Bozzi, S. (2011). Board Compensation and Ownership Structure: Empirical Evidence for Italian Listed Companies. Journal of Management and Governance, v. 15, p. 59-89.

Baum, C. F. (2001). Residual diagnostics for cross-section time series regression models. Stata Journal,1(1), 101104.

Bebchuk, L. A, Cohen, A., \& Ferrell, A. (2009). What Matters in Corporate Governance? Review of Financial Studies, 22(2), 783-827.

Bernini, E. J. (2010). Governança Corporativa e Governança Pública no ambiente de negócios regulados: Reflexões para o caso do setor elétrico brasileiro. Painel: Perspectivas para o ambiente regulado Cenário e Tendências. [ Palestra proferida em Seminários de Energia Elétrica Agências reguladoras: Papel e atuação no Setor Elétrico (ABDIB/EDUCORP)]. São Paulo, 2010. Recuperado em 7 agosto, 2013, de http://www.abdib.org.br/arquivos_comite//bernini_negocios_regulados.pdf

Beys, F. N. (2009). Análise das Práticas de Governança Corporativa do Setor de Energia Elétrica Brasileiro. 187 f. Dissertação (Mestrado em Administração) - Faculdade de Administração, Contabilidade e Economia, da Pontifícia Universidade Católica do Rio Grande do Sul (PUC-RGS), Porto Alegre, RS, Brasil.

Bhagat, S., \& Bolton, B. (2008). Corporate governance and firm performance. Journal of Corporate Finance, 14, $257-273$. 
Black, B. S., Carvalho, A. G. de, \& Gorga, É. (2012). What matters and for which firms for corporate governance in emerging markets? Evidence from Brazil (and other BRIK countries). Journal of Corporate Finance, 18(4), 934952.

Bohren, O., \& Odegaard, B.A. (2004). Governance and performance revisited. [ ECGI - Finance Working Paper No 28]. Disponível em: <http://ssrn.com/abstract=423461> Acesso em 03 mar. 2014.

Bortolon, P. M., Sarlo Neto, A., \& Santos, T. B. (2013). Custos de Auditoria e Governança Corporativa. R. Cont. Fin. - USP, 24(61), 27-36.

Braga-alves, M. V, \& Shastri, K. (2011). Corporate Governance, Valuation, and Performance: Evidence from a Voluntary Market Reform in Brazil. Financial Management, 139-157.

Bruno, V., \& Claessens, S. (2007). Corporate Governance and Regulation: Can There Be Too Much of a Good Thing ?, Journal of Financial Intermediation, 19(4) 461-482.

Carvalhal-da-Silva, A. L., \& Leal, R. P. C. (2005). Corporate índex, firm valuation and performance in Brazil. Revista Brasileira de Finanças, 3(1), 1-18.

Castro, N. J. de., Brandão, R., Dantas, G., \& Rosental, R. (2013). O Processo de Reestruturação do Setor Elétrico Brasileiro e os Impactos da MP 579. Texto de Discussão do Setor Elétrico n. 51 . Recuperado em 30 abril, 2014 , de http://www.nuca.ie.ufrj.br/gesel/tdse/TDSE-51.pdf.

Chhaochharia, V. \& Grinstein, Y. (2007). Corporate governance and firm value: The impact of the 2002 governance rules. Journal of Finance, 62, 1789-1825.

Claessens, S., Djankov, S., Fan, J. P. H., \& Lang, L.H. P. (2002). Disentangling the Incentive and Entrenchment Effects of Large Shareholdings. The Journal of Finance, 57(6), 2741-2771.

Correia, L. F. (2008). Um Índice de Governança para Empresas no Brasil. Tese de Doutorado em Administração, Centro de Pós-Graduação e Pesquisa em Administração, Faculdade de Ciências Econômicas, Universidade Federal de Minas Gerais, Belo Horizonte, MG, Brasil.

Correia, L. F., Amaral, H., \& Louvet, P. (2011). Um índice de avaliação da qualidade da governança corporativa no Brasil. Revista Contabilidade \& Finanças, 22, 45-63.

Cremers, M., \& Ferrell, A. (2010). Thirty years of corporate governance: firms valuations \& stock returns. CELS 2009 4th Annual Conference on Empirical Legal Studies Paper. Yale International Center for Finance Working Paper, n. 09-09. Recuperado em 12 dezembro, 2013, de http://ssrn.com/abstract=1413133

Dalton, D., Daily, C., Certo, S. T., \& Roengpitya, R. (2003). Meta-analysis of financial performance and equity: fusion or confusion?. Academy of Management journal, 46, 13-26.

Demsetz, H., \& Villalonga, B. (2001). Ownership structure and corporate performance'. Journal of Corporate Finance, $7(3), 209-33$.

Destefanis, S., Sena, V. (2007). Patterns of Corporate Governance and Technical Efficiency in Italian Manufacturing. Managerial and Decision Economics, 28, 27-40.

Durnev, A., \& Kim, E. H. (2005). To steal or not steal: firm attributes, legal environment and valuation. The Journal of Finance, 60(3), 1461-1493.

Dutra, M. G. L., \& Saito, R. (2001). Conselhos de administração: análise de sua composição em um conjunto de companhias abertas brasileiras. In XXV Encontra da Associação Nacional de Pós-Graduação em Administração (Enanpad), 2001, Campinas. Anais ... Rio de Janeiro: ANPAD, (CD ROM).

Erber, P. Modicidade Tarifária no Setor Elétrico. Recuperado em 30 abril, 2014 , de http://www.inee.org.br/informacoes_imprensa_artigo.asp?id=611\&Cat=info.

Ehikioya, B. I. (2009). Corporate governance structure and firm performance in developing economies: evidence from Nigeria. Corporate Governance, 9(3), 231-243.

Fahlenbrach, R., \& Stulz, R. M. (2009). Managerial Ownership dynamics and firm value. Journal of Financial Economics, n.92, p. 342-361.

Fischer, M. A. (2012). Governança corporativa analisada nos limites circunscritos da crise subprime: análise dos efeitos da crise na volatilidade das ações no novo mercado brasileiro e no prime standard alemão. Dissertação, Mestrado em Administração, Universidade Federal de Uberlândia, Programa de Pós-Graduação em Administração, Uberlândia, MG, Brasil.

Foley, C. F., \& Greenwood, R. (2010). The evolution of corporate ownership after IPO: The impact of Investor Protection. Review of Financial Studies, 23(3), 1231-1260.

Francis, J., Khurana, I., Pereira, R. (2005). Disclosure incentives and effects on cost of capital around the world. Acc. Rev. 80, 1125-1162. 
Gillan, L. S.; Hartzell, J. C. \& Starks, L. T. (2003). Explaining corporate governance: boards, bylaws and charter provisions. Weinberg Center for Corporate Governance, Working Paper N. 2003-03. Disponível em: http://ssrn.com/abstract=442740. Acesso em fev. 2014.

Gompers, P. A., Ishii, J. L., \& Metrick, A. (2003). Corporate Governance and Equity Prices. Quarterly Journal of Economics. 118(1), 107-155. Recuperado em 15 junho, 2013, de http://ssrn.com/abstract=278920

Gorga, É. C. R. (2005). Direito Societário Brasileiro e Desenvolvimento do Mercado de Capitais: uma perspectiva de "Direito e Economia". Tese de Doutorado, Programa de Pós-Graduação da Faculdade de Direito da Universidade de São Paulo, São Paulo, Brasil.

Gotardelo, D. R. (2006). Estudo das práticas de governança corporativa e o desempenho organizacional: uma análise envolvendo rentabilidade, volatilidade e valor de mercado. Dissertação de Mestrado em Administração, Faculdade de Administração da Pontifícia Universidade Católica de Minas Gerais (PUC-Minas), Belo Horizonte, MG, Brasil.

Holderness, C. G., \& Sheehan, D. P. (1988). The role of majoritary shareholders in publicly held corporations: an exploratory analysis. Jornal of Financial Economics, 20(1), 317-346.

Instituto Brasileiro de Governança Corporativa. (2009). Código das melhores práticas de governança corporativa. (4a ed.). São Paulo: IBGC.

Jensen, M., \& Meckling, W. (1976). Theory of the firm: managerial behavior, agency costs and ownership structure. Journal of Financial Economics, v.3, n. 4, p. 305-360.

Khanchel, I. (2007). Corporate governance: measurement and determinant analysis. Managerial Auditing Journal, 22(8), 740-760.

Johnson, S., Boone, P., Breach, A., \& Friedman, E. (2000). Corporate governance in the Asian financial crisis. Journal of Financial Economics, 58, (1), 141-186.

Klapper, L. F., \& Love, I. (2002). Corporate Governance, Investor Protection and Performance in Emerging Markets [Working Paper n. 2818]. World Bank Policy Research. Recuperado em 05 julho, 2013, de http://ssrn.com/abstract $=303979$.

Klapper, L. F., \& Love, I. (2004). Corporate Governance, Investor Protection, and Performance in Emerging Markets. Journal of Corporate Finance, 10, 703-728.

Lameira, V. J. (2007). Governança corporativa, risco e desempenho das companhias abertas brasileiras - uma análise do relacionamento entre as práticas de governança corporativa, o risco e o desempenho das companhias abertas brasileiras. Tese de Doutorado em Administração, Programa de Pós-Graduação em Administração de Empresas, Pontifícia Universidade Católica do Rio de Janeiro [ PUC-Rio], Rio de Janeiro, Brasil.

Lameira, V. J., Ness, W. L., Jr., \& Soares, T. D. (2005). Governança corporativa: impactos no valor das companhias abertas brasileiras. In: V Encontro Brasileiro de Finanças, Sociedade Brasileira de Finanças, 2005.

La Porta, R., Lopez-de-Silanes, F., \& Shleifer, A. (1999). Corporate ownership around the world. Journal of Financ, 54(2), 471-517.

La Porta, R., Lopez-de-Silanes, F., Shleifer, A., \& Vishny, R. W. (1998). Law and finance. Journal of Political Economy, 106(6), 1113-1155.

La Porta, R., Lopez-de-Silanes, F., Shleifer, A., \& Vishny, R. W. (2002). Investor protection and corporate valuation. The journal of Finance, 57(3), 1147-1170.

Leal, R. P. C., Carvalhal-da-Silva, A. L., \& Valadares, S. M. (2002). Estrutura de Controle das Companhias Brasileiras de Capital Aberto. Revista de Administração Contemporânea (RAC), 6 (1), 7-18.

Lemmon, M., \& Lins, K. (2001). Ownership Structure, Corporate Governance, and Firm Value: Evidence from the East Asian Financial Crisis. [Working Paper No 393]. William Davidson Institute, 3rd Annual Fin. Mkt. Dev. Conference, Hong Kong, China. Recuperado em 25 abril, 2014, de http://ssrn.com/abstract=265108.

Lima, G. A. S. F. de. (2009). Nível de Evidenciação x Custo da Dívida das Empresas Brasileiras. Revista Contabilidade \& Finanças, 20(49), 95-108.

Liu, C., Uchida, K., \& Yang, Y. (2012). Corporate governance and firm value during the global financial crisis:

Evidence from China. International Review of Financial Analysis, 21(1), 70-80.

Lopes, A. B., \& Walker, M. (2008). Firm-Level Incentives and the Informativeness of Accounting Reports: An Experiment in Brazil. Recuperado em 16 agosto, 2013, http://papers.ssrn.com/sol3/papers.cfm?abstract_id=1095781

Losekann, L. D. (2003) Reestruturação do setor elétrico brasileiro: cordenação e concorrência. Tese de Doutorado em Economia, Instituto de Economia, Universidade Federal do Rio de Janeiro, Rio de Janeiro, Brasil.

Macedo, M. A. S. \& Corrar, L. J. (2009). Análise comparativa do desempenho contábil-financeiro de empresas com boas práticas de governança corporativa no Brasil. In: XXXIII ENANPAD - Encontro Nacional da ANPAD, São paulo. 
Martins, G. A., \& Theóphilo, C. R. (2007). Metodologia da investigação científica para ciências sociais aplicadas. São Paulo: Atlas.

Martynova, M., \& Renneboog, L. D. R. (2010) A Corporate Governance Index: convergence and diversity of national corporate governance regulations. T/LEC Discussion Papers, v. 2010-012, 1-35.

Mello, J. S. F de. (2007). O impacto da governança corporativa no valor de mercado das companhias de capital aberto no Brasil - uma reaplicação. Dissertação de Mestrado em Administração, Centro de Pós-Graduação e Pesquisa em Administração, Faculdade de Ciências Econômicas, Universidade Federal de Minas Gerais, Belo Horizonte, MG, Brasil.

Morck, R., Shleifer, A., \& Vishny, R. W. (1988). Management ownership and market valuation: an empirical analysis. Journal of Financial Economics, v.20, p.293-316.

Nagar, A. L., \& Basu, S. R. (2002). Weighting sócio-economic indicators of human development: a latent variable approach. In: Ullah et al. (orgs.). Handbook of applied econometrics and statistical inference (Cap. 29). New York: Marcel Dekker.

Peixoto, F. M. (2012). Governança corporativa, desempenho, valor e risco: estudo das mudanças em momentos de crise. 2012. Tese de Doutorado em Administração, Centro de Pós-Graduação e Pesquisa em Administração, Faculdade de Ciências Econômicas, Universidade Federal de Minas Gerais, Belo Horizonte, MG, Brasil.

Peixoto, F. M., Amaral, H. F., Correia, L. F., \& Neves, J. C. C. (2013). Governança Corporativa e Valor de Mercado: o que mudou durante as crises ocorridas na primeira década do século XX|?. In: 13을 Encontro Brasileiro de Finanças, 2013, Rio de Janeiro. v. XIII. p. 15-30.

Rover, S., Tomazzia, E. C., \& Murcia, F. Dal-Ri. Explicações para a divulgação voluntária ambiental no Brasil utilizando a análise de regressão em painel. Revista de Administração da USP. São Paulo, 47(2), p.217-230.

Salmon, W. J. (2001). Prevenção de Crises: como engrenar o conselho. In: Experiências de Governança Corporativa. Rio de Janeiro: Campus.

Shleifer, A., \& Vishny, R. (1997). A survey of corporate governance. The journal of finance, 52(2), 737-783.

Siffert Filho, N. F., Alonso, L. de A., Chagas, E. B. das., Szuster, F. R., \& Sussekind, C. S. (2009). O papel do BNDES na expansão do setor elétrico nacional e o mecanismo de Project Finance. BNDES Setorial. Rio de Janeiro, n. 29, p. 3-36.

Silva, B. G. da. (2011). Evolução do setor elétrico brasileiro no contexto econômico nacional: uma análise histórica e econométrica de longo prazo. Dissertação de Mestrado, Programa de Pós-Graduação em Energia da Universidade de São Paulo (EP/FEA/IEE/IF). São Paulo, SP, Brasil.

Silveira, A. Di M. (2002). Governança Corporativa, desempenho e valor da empresa no Brasil. Dissertação de Mestrado, Universidade de São Paulo, São Paulo, SP, Brasil.

Silveira, A. Di M. (2004) Governança corporativa e estrutura de propriedade: determinantes e relação com o desempenho das empresas no Brasil. Tese de Doutorado em Administração, Programa de Pós-Graduação em Administração, Faculdade de Economia, Administração e Contabilidade da Universidade de São Paulo, São Paulo, SP, Brasil.

Silveira, A. Di M. (2006). Governança Corporativa e estrutura de propriedade: determinantes e relação com o desempenho das empresas no Brasil. São Paulo: Ed. Saint Paul.

Silveira, A. Di M., Barros, L. A. B. C., Famá, R. (2005). A Qualidade da Governança Corporativa Influencia o Valor das Companhias Abertas no Brasil? In: XXIX Encontro Nacional de Pós-Graduação e Pesquisa em Administração (ENANPAD), Brasília.

Sonza, I. B. (2012). Eficiências em Estruturas de propriedade concentradas e Compensação de Executivos: novas evidências para o Brasil. Tese de Doutorado em Administração, Programa de Pós-Graduação em Administração, Universidade Federal do Rio Grande do Sul (UFRGS), Porto Alegre, RS, Brasil.

Srour, G. (2005). Práticas Diferenciadas de Governança Corporativa: um estudo sobre a conduta e a performance das firmas brasileiras. Revista Brasileira de Economia, 59(4), 635-674.

Stulz, R. (1988). Managerial control of voting rights: Financing policies and the market for corporate control. Journal of Financial Economics, vol.20, p.25-54.

Tirole, J. (2006). The Theory of Corporate Finance. Princeton University Press.

Valadares, S. M., \& Leal, R. P. (2000). Ownership and Control Structure of Brazilian Companies. Revista Abante, 3(1), p. 29-56.

Velasquez, M. D. P. (2008). A influência da Governança Corporativa no Desempenho e na Estrutura de Capital das empresas listadas no N1, N2 e Novo Mercado da Bovespa. 195 f. Dissertação de Mestrado em Administração, Universidade Federal de Santa Maria (UFSM), Santa Maria, RS, Brasil. 
Vieira, M. F. da C. (2010). Governança Corporativa e Desempenho de Empresas: Novas Evidências do Caso Brasileiro. Dissertação de Mestrado, Escola de Pós-Graduação em Economia da Fundação Getúlio Vargas, Rio de Janeiro, Brasil.

Watts, R. L., \& Zimmerman, J. L. (1986). Towards a positive theory of the determination of accounting standards. Positive Accounting Theory. Englewood Cliffs: Prentice-Hall.

Wooldridge, J. M. (2002). Econometric Analysis of Cross Section and Panel Data. London: MIT Press.

Wong, S. C. Y. (2009). Uses and Limits of Conventional Corporate Governance Instruments: Analysis and Guidance for Reform (Integrated version). Private Sector Opinion, Global Corporate Governance Forum. Recuperado em 1 junho, 2013, de http://ssrn.com/abstract=1409370.

Yermack, D. (1996). Higher Market Valuation of Companies with a Small Board of Directors. Journal of Financial Economics, v. 40, p. 185-211.

Zheka, V. (2005). Corporate Governance, Ownership Structure and Corporate Efficiency: The Case of Ukraine. Managerial and Decision Economics, 26, 451-460.

Zonatto, V. C. da S., Santos, A. C. dos, Junior, M. M. R., \& Bezerra, F. A. (2011). Fatores determinantes para adoção das normas de contabilidade no Brasil: uma investigação em empresas públicas e privadas do setor de energia elétrica. Revista de Contabilidade e Organizações, 5(12), 26-47. 